\title{
Reciprocal continuous inhibition in rigidity of Parkinsonism
}

\author{
N. BATHIEN AND P. RONDOT
}

From Département de Physiologie, Faculté de Médecine Saint-Antoine, and Service de Neurologie, Faculté de Médecine Cochin Port-Royal, I rue Cabanis, Paris, France

SUMMARY A reciprocal continuous inhibition by flexor on extensor muscles was proved during Parkinsonian rigidity. Extensor motoneurone excitability was tested by Hoffmann's reflex and flexor activity was altered by lidocaine anaesthesia of the peroneal nerve(PN). During PN anaesthetic block, a gradual increase of Hoffmann's reflex was noted. It was statistically significant at the 15 th minute after lidocaine injection, and was maximum at the 30th minute. This reciprocal inhibition was considerable in 16 patients with Parkinsonism, as recorded before treatment. In normal subjects, it was small and non-significant. After one month's treatment with L-dopa at the usual therapeutic dose, this reciprocal inhibition greatly decreased in the same patients. The origin of this reciprocal continuous inhibition is discussed.

Rigidity in Parkinsonism expresses itself clinically in extensor as well as in flexor muscles (Babinski and Jarkowski, 1920). This was confirmed by strain gauge recordings during passive movements (Rondot et al., 1958). In both antagonistic muscle groups, the tonic stretch reflex should provoke a motoneurone hyperactivity, as Dimitrijevic and Nathan (1967) have observed in spasticity. Parodoxically, in Parkinsonian rigidity, extensor motoneurone excitability as tested by Hoffmann's reflex is normal or low (Angel and Hofmann, 1963; Delwaide, 1970). It may, therefore, be supposed that some central or peripheral inhibitory mechanism opposes motoneurone hyperactivity. One inhibitory mechanism is well known: it is the reciprocal inhibition transmitted by Ia fibres, as demonstrated in the animal (Lloyd, 1943; Eccles et al., 1956) and in normal man (Hagbarth, 1962; Liberson, 1965; Agarwal and Gottlieb, 1972). To find out if such an inhibition existed, we tried to see if blocking the antagonist afferent pathways altered extensor motoneurone excitability.

\section{Methods}

The tests were carried out on five normal subjects and 16 patients with Parkinsonian rigidity, 10 of whom were tested before and after treatment with L-dopa, this being given at the daily dose of $500 \mathrm{mg} \mathrm{L}$-dopa associated with $125 \mathrm{mg}$ of decarboxylase inhibitop (Ro 04-4602).

The age of normal subjects ranged from 22 to 35 years, that of Parkinsonism patients from 50 to 68 years.

The flexor (tibialis anterior, TA) and extenso (soleus, Sol) muscle groups of the foot were chosen, as extensor motoneurone excitability is easily assessed by Hoffmann's technique (HR), and blocking of antagonist muscles is easily done by injection of local anaesthetic into the peroneal nerve at the fibular head level. Comparing the HR results for extensors before and after peroneal nerve anaesthesia, one can deduce whether or not an inhibition exists which affects extensor motoneurones and is due to afferent influxes transmitted by the peroneal nerve.

The HR in extensor motoneurones of the foot was tested according to the technique standardised at the International Congress of EMG in Brussels (Hugon, 1973). The subject was seated with knee extended at an angle of $120^{\circ}$ and ankle at $100^{\circ}$. The tibial nerve was stimulated in the popliteal fossa by rectangular electric pulses of one millisecond duration at a frequency of 0.3 per sec. The contraction of the soleus muscle was recorded by surface electrodes placed on the midline at the lower and middle third of the calf.

The peroneal nerve (PN) was blocked by a 10 to $20 \mathrm{ml}$ injection of $1 \%$ lidocaine solution at fibular head level.

Each test consisted of two stages: 
1. $\mathrm{H} \max / \mathrm{M}$ max ratio, and $\mathrm{HR}$ at its $1 / 2$ maximum amplitude (HR 1/2 max) were established before lidocaine injection.

2. After peroneal nerve anaesthesia, the mean amplitude of HR (1/2 max) was measured every five minutes. At the 30th minute, the $\mathrm{H} \max / \mathrm{M}$ max ratio was again established.

Means and standard deviations of data were computed for each situation: control (before PN block) then after PN block, in patients before and after one month of treatment with L-dopa. Student's $t$ test was used for comparison between means. The analysis of covariance was applied in order to study the effect of L-dopa.

\section{Results}

\section{SOLEUS MUSCLE H REFLEX DURING ANAESTHETIC}

BLOCK OF PERONEAL NERVE

Figure 1 shows the results obtained in a Parkinsonism patient. The control $\mathrm{H} \max / \mathrm{M} \max$ ratio was $47 \%$, a substantially normal value. After PN block the HR (1/2 max) value increased gradually, and at the 30 th minute it reached double its amplitude before blocking.

Figure 2 shows that facilitation of Sol HR (1/2 max) was correlated with the TA response provoked by PN stimulation above the anaesthetic block. It was significant when TA response decrease reached $30 \%$. It was maximum when TA response was minimum. Stability of the Sol M response guarantees the good conditions of exploration of the soleus motor nucleus excitability and of adequate PN blocking.

Figure 3 shows the results recorded in five normal subjects and 16 patients with Parkinsonism. Hoff-

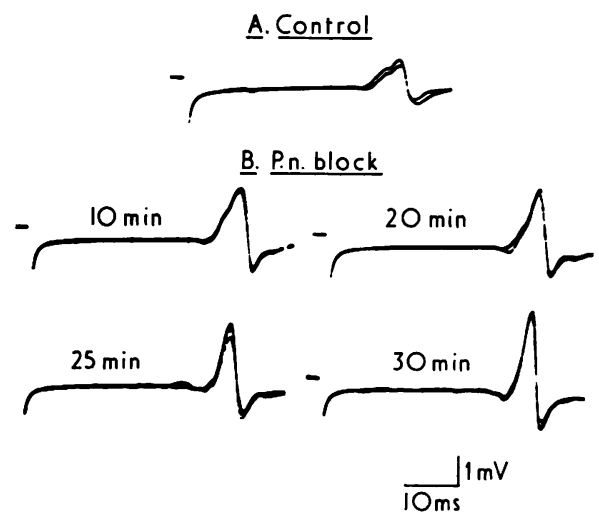

Fig. 1 Facilitation of Hoffmann's reflex in Parkinson's disease after anaesthetic block of peroneal nerve $(P N)$. $A$ and $B$ show separate $H$ responses as recorded before anaesthetic injection (control) and 10,20, 25, and 30 minutes later.

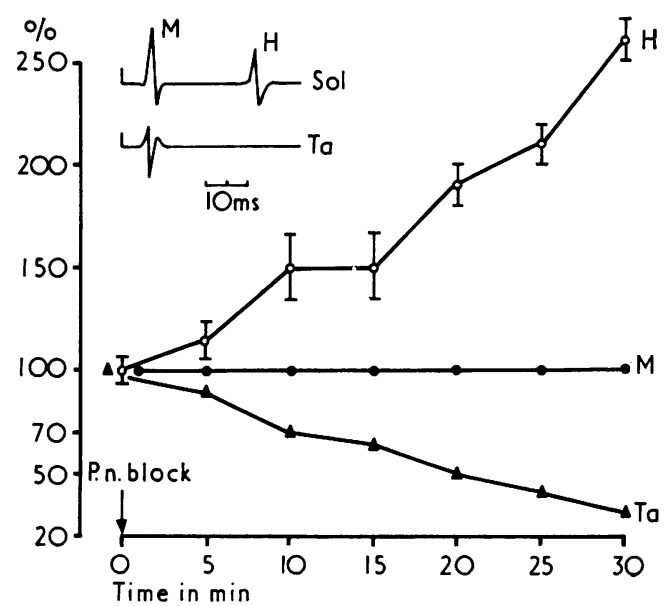

Fig. 2 Effects of peroneal nerve block (PN block) on $H$ reflex and tibialis anterior (TA) motor response. $\bigcirc-\bigcirc$ denotes the facilitating effect of $P N$ block on $H$ responses $(H) ; \triangle-\triangle$ shows the depression of TA motor response. Soleus muscle (Sol) direct motor response $(M)$ amplitude (O) remains unchanged. Abscissa represents anaesthetic blocking time.

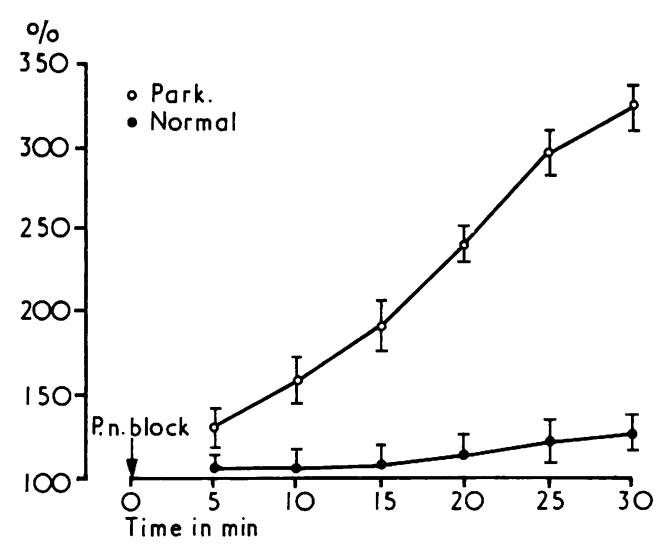

Fig. 3 Comparison of PN block effects on $\mathrm{H}$ reflex of 16 Parkinsonism patients and five healthy subjects. Mean values and two standard deviations are shown at each blocking time.

mann's reflex (1/2 max) in normal subjects was not significantly modified by PN block. In patients with rigidity, mean amplitude of HR (1/2 max) increased considerably. Thirty minutes after injection of anaesthetic the HR mean amplitude reached $327 \%$ of the control value. In the population of 10 patients used as controls for the study of $\mathrm{L}$-dopa effects before treatment (Table 1), a significant HR (1/2 max) increase was observed at the 15 th minute after PN block. It reached its maximum towards the 30th minute and 
Table 1 Quantitative evaluation of $H$ reflex amplitude after PN block in patients with Parkinsonism

\begin{tabular}{llllllll}
\hline & \multicolumn{7}{l}{ H reflex amplitude $(m V)$ after PN block $(\mathrm{min})$} \\
\cline { 2 - 8 } Patient & Control & 5 & 10 & 15 & 20 & 25 & 30 \\
\hline FIL & 1.0 & 2.0 & 3.0 & 4.0 & 4.0 & 5.0 & 6.0 \\
RIC & 0.5 & 0.5 & 0.8 & 1.2 & 2.0 & 2.8 & 3.0 \\
SAM & 1.0 & 1.2 & 2.0 & 2.5 & 3.1 & 3.5 & 3.5 \\
MAR & 0.8 & 1.0 & 1.3 & 1.5 & 2.0 & 3.5 & 3.5 \\
OLI & 2.1 & 2.5 & 2.5 & 3.0 & 4.0 & 4.2 & 4.5 \\
ESP & 1.0 & 1.0 & 1.5 & 2.0 & 3.0 & 3.5 & 3.5 \\
MEU & 2.0 & 2.0 & 2.5 & 3.0 & 3.0 & 3.0 & 3.0 \\
FOR & 2.0 & 3.0 & 3.0 & 3.5 & 4.0 & 4.2 & 5.0 \\
DEB & 0.5 & 0.5 & 0.7 & 1.0 & 2.5 & 3.0 & 3.5 \\
HAL & 1.0 & 1.0 & 1.3 & 2.0 & 2.3 & 3.0 & 3.4 \\
X & 1.19 & 1.47 & 1.86 & 2.37 & 2.99 & 3.57 & 3.89 \\
SD & 0.64 & 0.85 & 0.86 & 1.00 & 0.79 & 0.70 & 0.97 \\
SE & 0.19 & 0.26 & 0.26 & 0.31 & 0.24 & 0.21 & 0.30 \\
HR/Control & & & & & & & \\
$\%$ & & 24 & 56 & 99 & 151 & 300 & 327 \\
P 100 & & NS & NS & $*$ & $* *$ & $* * *$ & $* * *$ \\
\hline
\end{tabular}

$\mathrm{X}=$ mean value; $\mathrm{SD}=$ standard deviation; $\mathrm{SE}=$ standard error; HR $=$ Hoffmann's reflex; ${ }^{*} \mathrm{P}<0.05 ;{ }^{* *} \mathrm{P}<0.01 ;{ }^{* * *} \mathrm{P}<0.001$.

remained level beyond the first hour. For the patient's comfort and to avoid unwanted effects, recording was not continued beyond one hour after PN block.

By comparison with normal subjects, a decrease of HR was noted in Parkinsonian rigidity. This HR inhibition decreased $\mathrm{H}$ max/ $\mathbf{M}$ max after PN block. The mean $\mathrm{H} / \mathrm{M}$ ratio was $59.0 \pm 5.8 \%$ in normal subjects. It was $12.7 \pm 4.0 \%$ in Parkinsonism patients. It increased after PN block, to reach $30.4 \pm 0.8 \%$.

\section{ACTION OF L-DOPA}

After one month's treatment by L-dopa, the 10 Parkinsonism patients, whose results were reported in Table 1 , were tested by the same technique.

Before PN block, the mean $\mathrm{H}$ max/M max ratio was $31.0 \pm 0.65 \%$.

After PN block, this ratio reached $35.5 \pm 10.5 \%$. This increase is not significant. However, the HR (1/2 max) was still increased by nerve block, although very much less than before treatment with L-dopa (Table 2 and Fig. 4).

\section{COMPARATIVE STUDY BEFORE AND AFTER TREATMENT}

AND BEFORE AND AFTER ANAESTHETIC BLOCK

The changes in HR (1/2 max) were studied comparatively in the same group of 10 patients first before and after L-dopa treatment with no anaesthetic block, and then before and after anaesthetic block. Covariance analysis (Table 3 ) showed that in both cases, the HR (1/2 max) increased significantly.

Moreover, if the curve of HR (1/2 max) increase after PN block in untreated patients is compared with that of patients treated with L-dopa, one notes that the slope of the curve is different in the two different
Table 2 Effect of $\mathrm{L}$-dopa on modifications of $H$ reflex induced by $P N$ block in patients with Parkinsonism

\begin{tabular}{llllllll}
\hline & \multicolumn{7}{l}{ H reflex amplitude $(m V)$ after $P N$ block $($ min $)$} \\
\cline { 2 - 8 } Patient & Control & 5 & 10 & 20 & 25 & 25 & 30 \\
\hline FIL & 2.0 & 2.0 & 2.5 & 3.0 & 3.0 & 3.5 & 4.5 \\
RIC & 2.5 & 2.5 & 3.0 & 3.0 & 3.2 & 3.5 & 4.0 \\
SAM & 4.0 & 4.0 & 4.0 & 4.5 & 4.5 & 4.5 & 5.0 \\
MAR & 3.0 & 3.0 & 3.0 & 3.5 & 3.5 & 4.0 & 4.0 \\
OLI & 3.5 & 3.5 & 3.5 & 3.5 & 3.7 & 4.0 & 4.0 \\
ESP & 4.0 & 4.0 & 4.0 & 4.2 & 4.2 & 4.5 & 4.5 \\
MEU & 3.5 & 3.5 & 3.5 & 3.7 & 3.7 & 3.7 & 4.0 \\
FOR & 3.0 & 3.0 & 3.0 & 3.5 & 3.5 & 4.0 & 4.0 \\
DEB & 2.0 & 2.0 & 2.0 & 2.5 & 2.5 & 3.0 & 3.5 \\
HAL & 3.0 & 3.0 & 3.0 & 3.2 & 3.2 & 3.5 & 3.5 \\
X & 3.05 & 3.05 & 3.15 & 3.46 & 3.50 & 3.82 & 4.10 \\
SD & 0.72 & 0.72 & 0.62 & 0.58 & 0.57 & 0.47 & 0.45 \\
SE & 0.22 & 0.22 & 0.19 & 0.18 & 0.17 & 0.14 & 0.14 \\
HR/Control & & & & & & \\
\% & & 0 & 3 & 13 & 15 & 25 & 34 \\
P & & & NS & NS & $*$ & $*$ & $* *$ \\
\hline
\end{tabular}

Values as in Table 1.

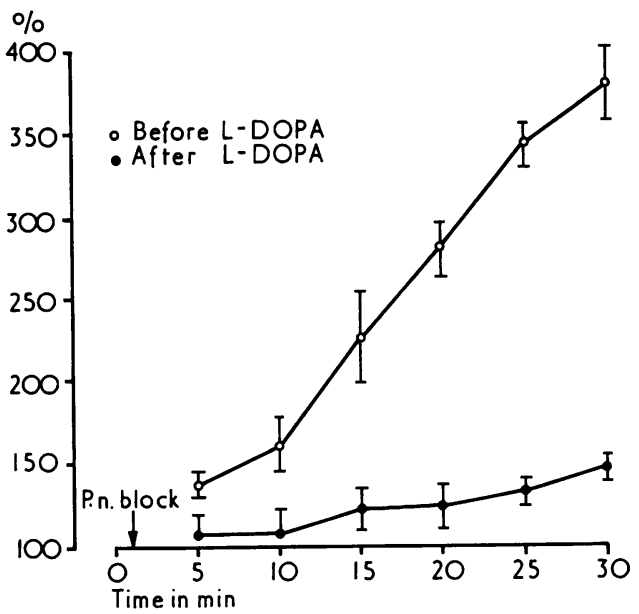

Fig. 4 Comparison of $P N$ effects on $H$ reflex in 10 Parkinsonism patients before and after treatment by L-dopa over a period of one month. Mean values and two standard deviations are shown at each blocking time.

Table 3 Analysis of covariance for data of Tables 1 and 2 (HR amplitude of control and 30th minute after $P N$ block were selectively computed)

\begin{tabular}{lllll}
\hline Source of variation & Variance & Df & $F$ & Significance \\
\hline Before/after L-dopa & 29.640 & 1 & 56.045 & $<0.001$ \\
Before/after PN block & 40.890 & 1 & 77.317 & $<0.001$ \\
\hline
\end{tabular}

$D f=$ degree of freedom; $F=F$ ratio. 
circumstances: the regression coefficient is 0.088 before and 0.035 after treatment.

To sum up, $\mathbf{H} \max / \mathbf{M} \max$ ratio decreased in Parkinsonian rigidity. After anaesthetic block of the nerve to the antagonist flexor muscles, a considerable increase of $\mathrm{HR}$ was recorded.

After one month's treatment with L-dopa, reflex excitability was higher, and the HR facilitation observed after PN block was less sharp.

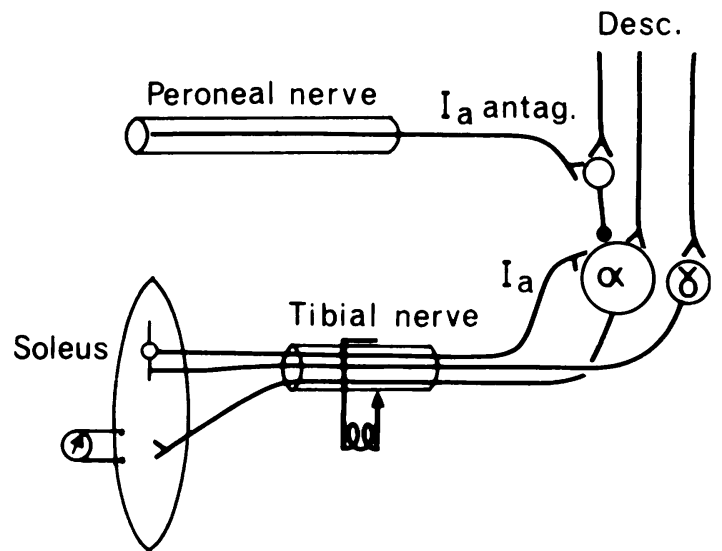

Fig. 5 Schematic diagram of pathways under

investigation. The descending pathway is not necessarily monosynaptic. See text.

\section{Discussion}

Procaine anaesthetic block has often been used on mixed nerves to separate the effects transmitted by small fibres from those transmitted by large ones (Matthews and Rushworth, 1957; Nathan and Sears, 1961; Gassel and Diamantopoulos, 1964). In this study, no attempt was made to obtain such selective action; on the contrary, the quantity of procaine injected was meant to-and did-block all the nerve fibres. Thus, in the example in Fig. 2, the TA action potential amplitude evoked by nerve stimulation decreased gradually after local injection of the anaesthetic agent. Furthermore the soleus HR increased significantly only when the TA motor response decreased by $50 \%$ of its control value. This was not noted in cases where the PN block was inactive.

These results led us to the conclusion that soleus $H R$ increase is due to the suppression of a reciprocal inhibition transmitted by the fibres of the nerves coming from the antagonist muscles. We suggest they are Ia fibres from muscle spindles of flexor muscles. The nociceptive cutaneous influx is not involved, as the nociceptive cutaneous polysynaptic reflex is normal in Parkinsonian rigidity (Bathien and
Bourdarias, 1972). The possibility that such influxes could travel along these fibres at rest in the absence of all stimulation is, therefore, excluded.

Soleus HR changes were obtained only after several minutes' latency as a result of PN anaesthesia, although lidocaine acts earlier on small fibres. This inhibition is not transmitted by Ib fibres either, since these activate antagonist muscles. On the other hand, the role of flexion reflex afferent fibres (FRA) should be considered: they facilitate flexor muscles motoneurones and inhibit extensor ones.

It has been shown, however (Anden et al., 1966), that DOPA releases a long latency flexion reflex. This should therefore increase extensor motoneurone inhibition whereas the contrary is noted after L-dopa treatment. Tonic inhibition of extensor motoneurones is, therefore, quite likely to be transmitted by the disynaptic pathway of Ia fibres from spindles of flexor muscles (Eccles et al., 1956). The latency of at least 10 minutes which precedes the cessation of extensor motoneurone inhibition after local anaesthesia (Fig. 2) is due to the delayed action of the anaesthetic agent on large fibres. This delayed action also accounts for the fact that the TA action potential evoked by the stimulation of motor nerve large fibres decreases at the same time as the extensor motoneurone HR increase.

The continuous Ia reciprocal inhibition accounts, in our opinion, for the previously mentioned paradox: the values of the $\mathrm{H} \max / \mathrm{M}$ max ratio in the patient with Parkinsonism are normal or decreased (Angel and Hofmann, 1963; Delwaide, 1970), whereas using the double shock technique, the late facilitation of the $H$ recovery curve is increased. These abnormalities of HR, qualitative as well as quantitative, are of the same order as those reported in spastic patients (Takamori, 1967; Zander-Olsen and Diamantopoulos, 1967; Delwaide, 1970). The decrease of HR is therefore the result of an inhibition from the antagonist muscles which exists at rest while no electrical activity is recorded on those muscles.

The results observed on the soleus HR after treatment with L-dopa are comparable with those recorded in normal subjects. This action of L-dopa could be attributed to the decrease in tonic activity of the foot flexor muscles, which provoked a decrease in Ia afferent fibre activity from these muscles. Recent electrophysiological data require consideration of the associated role of another factor. It has been shown that there is convergence on the reciprocal Ia inhibitory pathway of excitation from descending pathways: corticospinal (Lundberg and Voohoeve, 1962), rubrospinal (Hongo et al., 1969) and vestibulospinal (Grillner et al., 1966). Should the suprasegmental control be disturbed in Parkinsonian rigidity, L-dopa might also act by correcting this. 


\section{References}

Agarwal, G. C., and Gottlieb, G. L. (1972). The muscle silent period and reciprocal inhibition in man. Journal of Neurology, Neurosurgery, and Psychiatry, 35, 72-76.

Anden, N. E., Jukes, M. G. M., Lundberg, A., and Vyklicky, L. (1966). The effect of Dopa on the spinal cord. I. Influence on transmission from primary afferents. Acta Physiologica Scandinavica, 67, 373-386.

Angel, R. W., and Hofmann, W. W. (1963). The H reflex in normal, spastic and rigid subjects. Archives of Neurology, 8, 591-596.

Babinski, J., and Jarkowski, J. (1920). Etude de la radieur musculaire dans un cas de syndrome parkinsonien consécutif à une encéphalite epidémique. Réaction des antagonistes. Revue Neurologique, 1, 564-570.

Bathien, N., and Bourdarias, H. (1972). Lower limb cutaneous reflexes in hemiplegia. Brain, 95, 447-456.

Delwaide, P. J. (1970). Étude Expérimentale de l'Hyperréflexie Tendineuse en Clinique Neurologique. Thèse Arscia, Bruxelles.

Dimitrijevic, M. R., and Nathan, P. W. (1967). Studies of spasticity in man. I. Some features of spasticity. Brain, 90, $1 ; 30$.

Eccles, J. C., Fatt, P., and Landgren, S. (1956). Central pathway for direct inhibitory action of impulses in largest afferent nerve fibres to muscle. Journal of Neurophysiology, 19, 75-98.

Gassel, M. M., and Diamantopoulos, E. (1964). The Jendrassik maneuver. I. The pattern of reinforcement of monosynaptic reflexes in normal subjects and patients with spasticity or rigidity. Neurology (Minneap.), 14, 555-560.

Grillner, S., Hongo, T., and Lund, S. (1966). Interaction between the inhibitory pathways from the Deiters' nucleus and Ia afferents to flexor moto-neurones. Acta Physiologica Scandinavica, 68, suppl. 277, 60.

Hagbarth, K. E. (1962). Post-tetanic potentiation of myotatic reflexes in man. Journal of Neurology, Neurosurgery, and Psychiatry, 25, 1-10.

Hongo, T., Jankowska, E., and Lundberg, A. (1969). The rubrospinal tract. II. Facilitation of interneuronal transmission in reflex paths to motoneurones. Experimental Brain Research, 7, 365-391.

Hugon, M. (1973). Methodology of the Hoffmann reflex in man. In New Developments in Electromyography and Clinical Neurophysiology, vol. 3, pp. 277-293. Edited by J. E. Desmedt. Karger: Basel.

Liberson, W. T. (1965). Experiment concerning reciprocal inhibition of antagonists elicited by electrical stimulation of agonists in normal individual. American Journal of Physiological Medicine, 44, 306-308.

Lloyd, D. P. C. (1943). Neuron patterns controlling transmission of ipsilateral hind limbes reflex. Journal of Neurophysiology, 6, 293-326.

Lundberg, A., and Voorhoeve, P. (1962). Effects from the pyramidal tract on spinal reflex arcs. Acta Physiologica Scandinavica, 56, 201-219.

Matthews, P. B. C., and Rushworth, G. (1957). The relative sensitivity of muscle nerve fibres to procaine. Journal of Physiology (London), 135, 263-269.

Nathan, P. W., and Sears, T. A. (1961). Some factors concerned in differential nerve block by local anaesthetics. Journal of Physiology (London), 157, 565-580.

Rondot, P., Dalloz, J. C., and Tardieu, G. (1958). Mesure de la force des réactions musculaires à l'étirement passif au cours des raideurs pathologiques par lésions cérébrales. Revue Française. Études Cliniques et Biologiques, 3, 585-592.

Takamori, M. (1967). H reflex study in upper motoneuron diseases. Neurology (Minneap.), 17, 32-40.

Zander-Olsen, Z., and Diamantopoulos, E. (1967). Excitability of spinal motor neurones in normal subjects and patients with spasticity. Journal of Neurology, Neurosurgery, and Psychiatry, 30, 325-331. 